Dicle Tıp Dergisi / Dicle Med J (2019) 46 (3) : 603-608

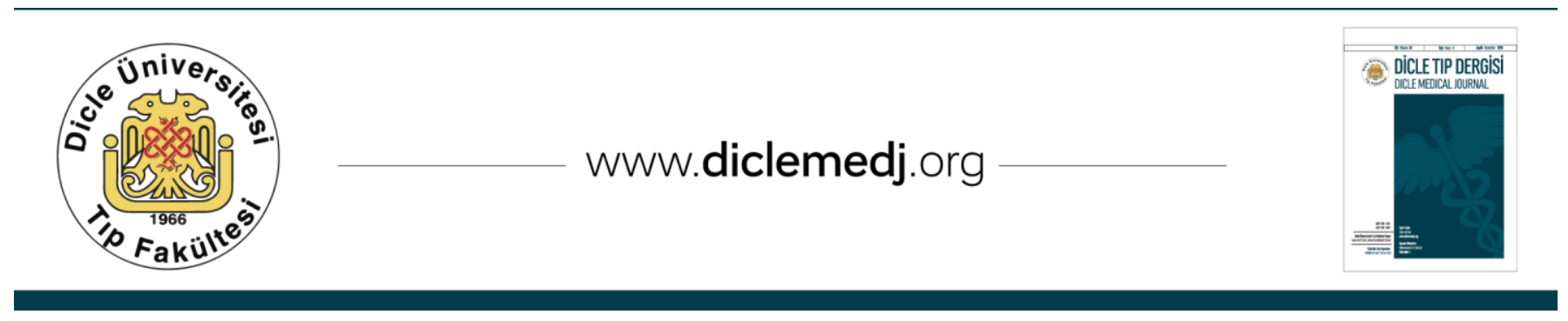

Olgu Sunumu / Case Report

\title{
Aicardi Sendromlu Kardeşler: Olgu Sunumu
}

\author{
Veysel Kaplanoğlu' ${ }^{1}$, Hatice Kaplanoğlư ${ }^{2}$, Havva Akmaz Ünlü ${ }^{3}$ \\ 1 Sağllk Bilimleri Üniversitesi Keçiören Eğitim ve Araştırma Hastanesi, Radyoloji, Ankara, Türkiye ORCID: 0000-0002-1376-0469 \\ 2 Sağlık Bilimleri Üniversitesi Dıșkapı Yıldırım Beyazıt Eğitim ve Araștırma Hastanesi, Radyoloji, Ankara, Türkiye ORCID: 0000-0003-1874-8167 \\ 3 Sağllk Bilimleri Üniv Ankara Çocuk Sağlığı Hastalıkları Hemotoloji Onkoloji Eğitim Araş Hastanesi, Radyoloji, Ankara, Türkiye ORCID: 0000-0002-0291-3589
}

Geliş:19.03.2019; Revizyon: 04.04.2019; Kabul Tarihi: 24.04.2019

Öz

Aicardi sendromu infantil spazm, korpus kallozum agenezisi, koryoretinallakün başta olmak üzere oküler anormalliklerve motor mentalretardasyonla karakterize ciddi doğumsal bir sendromdur. Hastalığın tanısı klinik bulgular ile konulmaktadır. Elektroensefalografi, manyetik rezonans görüntüleme bulguları ve oftalmolojik muayene tanıda yardımcidır.

Aicardi sendromlu hastalarda genellikle ilk sorun nöbet ve motor-mental retardasyon olarak karşımıza çıkmaktadır. $\mathrm{Bu}$ çalışmada akraba evliliği sonucunda dünyaya gelen, motor-mental retardasyon, göz bulgularının, korpus kallozum hipoplazisi, interventriküler kistin izlendiği Aicardi sendromu tanısı alan iki kardeş olgu sunulmuştur.

Anahtar kelimeler: Aicardi sendromu, korpus kallozum agenezisi; göz anomalileri, epilepsi, MRG.

\section{Brothers with Aicardi Syndrome: Case Report}

\begin{abstract}
Aicardi's syndrome is a severe congenital syndrome characterized by infantile spasm, corpus callosum agenesis, ocular abnormalities, especially chorioretinal lacuna, and motor mental retardation. The diagnosis of the disease is made by clinical findings. Electroencephalography, magnetic resonance imaging findings and ophthalmologic examination are helpful in the diagnosis. The first problem in patients with Aicardi syndrome is seizure and motormental retardation. In this study, two siblings who were born as a result of consanguineous marriages and who were diagnosed Aicardi syndrome with mental-motor retardation, ocular abnormalities, corpus callosum hypoplasia and interventricular cyst were presented.
\end{abstract}

Keywords: Aicardi's syndrome, corpus callosum agenesis; eye anomalies, epilepsy, MRI.

DOI: $10.5798 /$ dicletip.620675

Yazışma Adresi / Correspondence: Hatice Kaplanoğlu, Sağlı Bilimleri Üniversitesi Dışkapı Yıldırım Beyazıt Eğitim ve Araştırma Hastanesi, Radyoloji Bölümü, TR-06100 Ankara, Türkiye, e-mail: hatice.altnkaynak@yahoo.com.tr 


\section{GİRIŞ}

Aicardi sendromu ilk kez Jean Aicardi tarafından 1965 yılında tanımlanmıştır. İnfantil spazm, koryoretinallakünler ve korpus kallozum agenezisi sendromun klasik triadını oluşturmaktadır. Doğumsal ve nadir görülen ciddi seyirli bir hastalıktır ${ }^{1}$. Genellikle kız çocuklarında ve çok nadiren 47,XXY karyotipine sahip erkeklerde gözüken, $X$ kromozomundaki dominant de novo mutasyonların sebep olduğu düşünülen bir hastalıktır ${ }^{2}$. Hafif veya orta derecede mental retardasyon sıklıkla eşlik eder ${ }^{2}$. Fokal nöbet görülmesi daha yaygındır. Eşlik eden diğer sık bulgular oküler kolobom, kostovertebral anomaliler, elektroensefalografi bozuklukları, kognitif bozukluk ve psikomotor gelişme geriliğidir $^{2,3}$. SSS tutulumu, kallozal displazi, intrakraniyal kistler, polimikrogri ve ağır serebellar anomaliler şeklinde olabilmektedir ${ }^{2,4}$.

Biz burada çocukluk çağı döneminde klinik ve radyolojik bulgular ile tanı koyduğumuz iki Aicardi Sendromlu kardeşi sunacağız.

\section{OLGU 1}

Birinci derece kuzen evliliği ile anne-babanın ilk çocuğu olan 11 yaşındaki erkek olgunun, normal spontan vajinal doğumla miadında doğduğu öğrenildi. Prenatal ve perinatal öyküsüne ailenin yabancı uyruklu olması nedeniyle ulaşılamadı. Üç yaşında yürümeye başladığı ve nöromotor gelişiminin doğduğundan beri geri olduğu öğrenildi. Nörolojik muayenede; nöromotor gelişimi yaşına göre geri olup, mentalretarde olduğu, konuşamadığı ve söylenenleri anlamadığı görüldü. Derin tendon refleksleri hiperaktifti. Yapılan göz muayenesinde sol gözde nistagmus vardl, ezotropya ve hipertropya saptandı. Bilateral optik disk minimal soluk olarak izlendi.

Diğer sistem muayeneleri normal sinırlarda bulundu. Laboratuvar incelemelerinde; tam kan sayımı, biyokimya, tiroid stimülan hormon, serbest T3 T4 ve kreatin fosfokinaz düzeyleri normal bulundu. TORCH tetkiklerinde bir özellik yoktu. Olgunun idrar organik asitleri, kan ve beyin omurilik sivisında bakılan aminoasitler, kan amonyak, laktat, pirüvat, biyotinidaz aktivitesi normal saptandı. Direkt ekstremite, telekardiyogram ve akciğer grafilerinde özellik yoktu. Batın ultrasonografisinde özellik saptanmadı. Elektrokardiyogram ve ekokardiyografi tetkiklerinde özellik yoktu. Olgunun, elektroensefalografi (EEG) sinde; her iki frontotemporal lobda multifokal epileptik aktivite izlendi. Etiyolojiye yönelik istenilen kraniyal MRG'de Frontal düzeyde polimikrogri vardı (şekil 1). Serebellar vermisin hipoplazik olduğu, hemisferlerde inferior kesimde fokal serebellar displazi ile uyumlu fissür -sulkal morfolojide asimetri ve bozulma izlendi (şekil 2a). Sol serebellomeduller sisternde $3 \times 2 \mathrm{~cm}$ boyutlarda araknoid kist saptandı (şekil 2a, b). Korpus kallozum hipoplazisi, interpedinküler sisternde $\quad 5 \times 3.5 \quad \mathrm{~cm} \quad$ boyutlarında interhemisferik kist (şekil 3), lateral ventriküllerin medial kesimleri boyunca nodüler subependymal gri cevher heterotopisi izlendi (şekil 4). Mevcut bulguları ile olgu Aicardi sendromu olarak değerlendirildi.

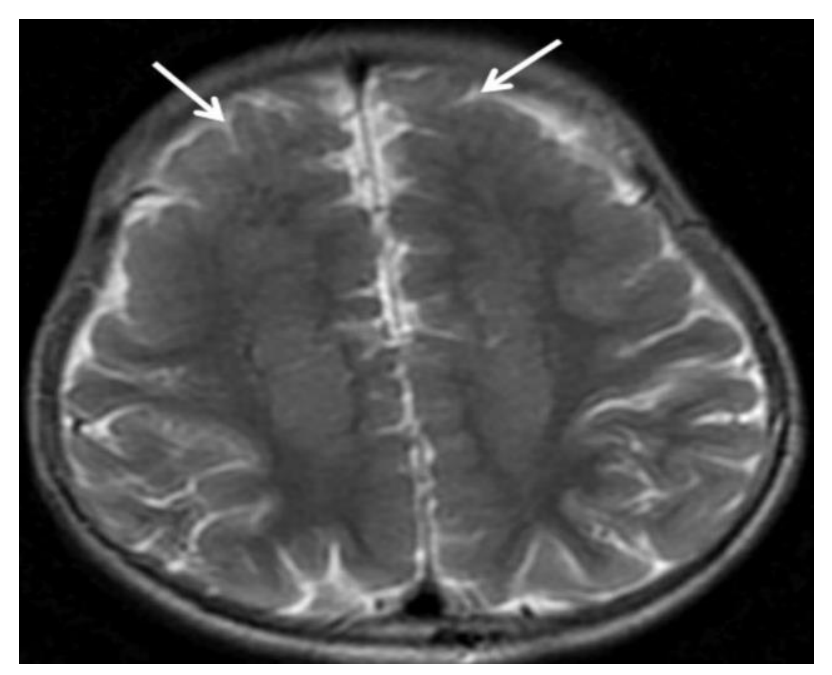

Şekil 1. Aksiyal T2 ağırlık görüntüde, her iki frontal lobda multiple küçük gyruslar (polymikrogri) izleniyor (oklar). 

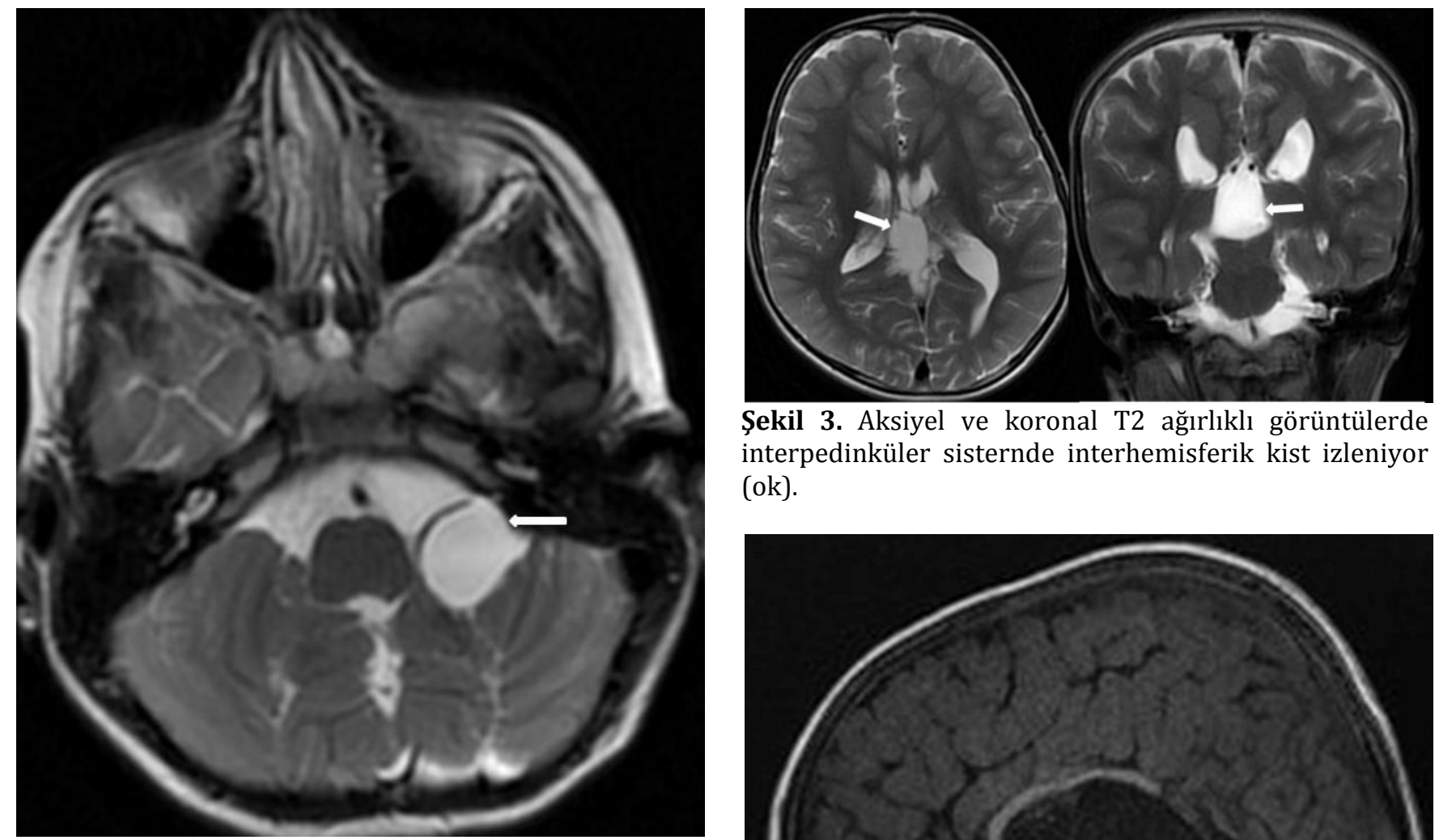

Şekil 3. Aksiyel ve koronal T2 ağırlıklı görüntülerde interpedinküler sisternde interhemisferik kist izleniyor (ok).

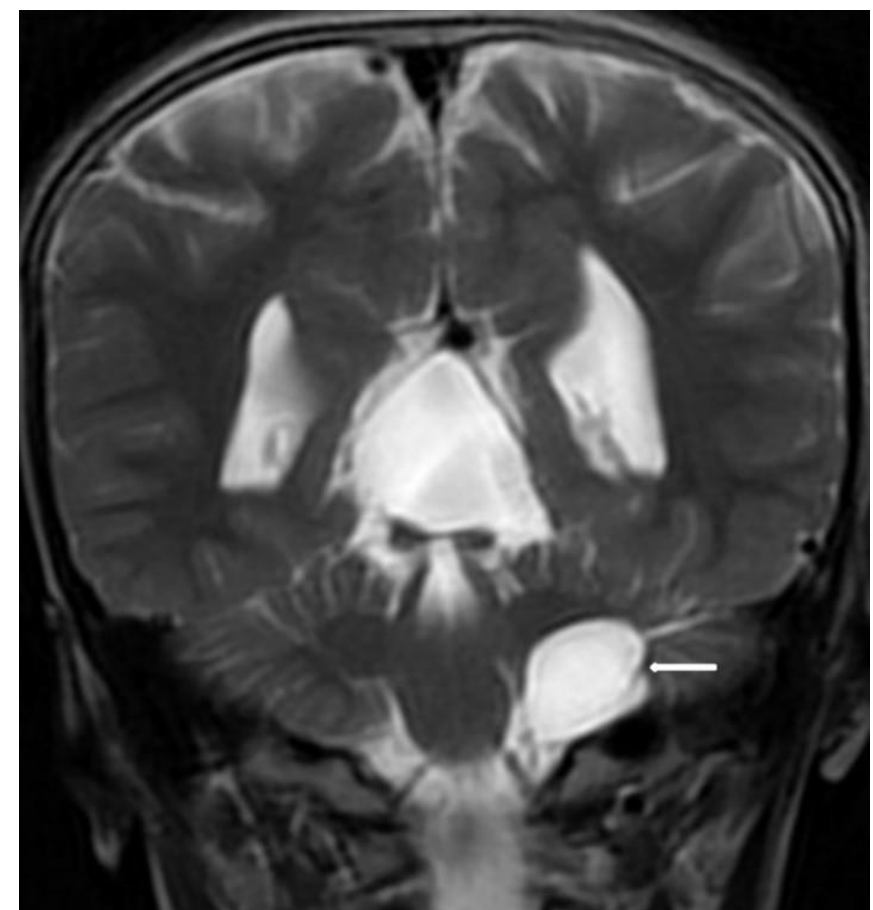

Şekil 2. a.Serebellarvermistehipoplazi ve fokalserebellar displazi; b. sol serebellomeduller sisterndearaknoid kist (oklar) izleniyor

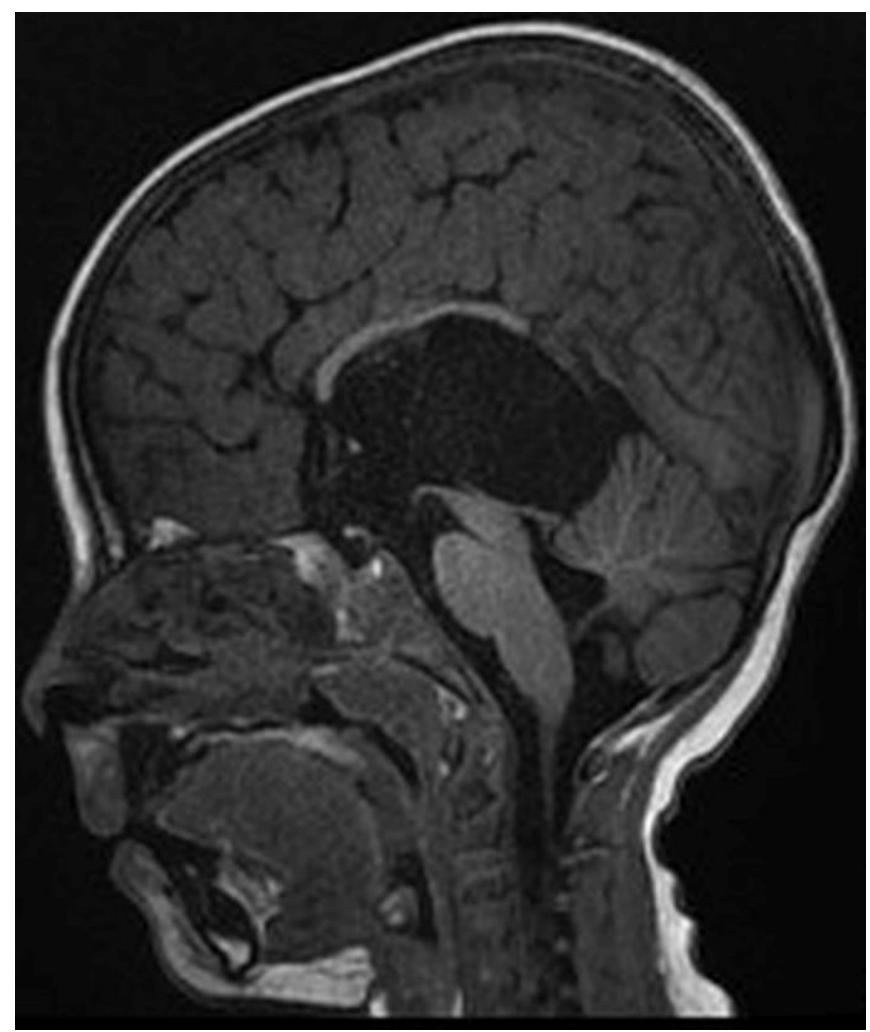

Şekil 4. Aksiyal T2 ağırlık görüntüde, lateral ventriküllerin medial kesimleri boyunca nodüler subependimal gri cevher heterotopisi izleniyor (ok).

\section{OLGU 2}

Altı yaşında kız olgu, birinci olgunun ikinci kardeși olup normal spontan vajinal doğumla miadında doğdu. Prenatal ve perinatal öyküde özelliği olmayan olgunun motor ve mental gelişim basamaklarında gerilik vardı. Olgu orta düzeyde mental retarde, bir iki kelimelik basit cümleler kurabiliyordu. Nörolojik muayenesi 
normal olarak değerlendirildi. Yapılan göz muayenesinde ambliyopi ve her iki gözde koryoretinal lakünler saptandı. Kemik surveyinde torokolomber vertebralarda skolyoz, T6 ve T7 vertebralarda hemivertebra, L2 ve L3'te kelebek vertebra anomalisi görüldü. Olgunun serum ve beyin-omurilik sıvisindan yapılan aminoasit düzeyleri, plazma karnitin, açil-karnitin tetkikleri, Tandem-MS taraması serum laktat, pirüvat, idrar organik asitleri normal saptandı. Telekardiyogram ve akciğer grafilerinde özellik yoktu. Batın ultrasonografisinde özellik saptanmadı. Elektrokardiyogram ve ekokardiyografi tetkiklerinde özellik yoktu. Etiyolojiye yönelik istenilen kraniyal MRG'de; serebellar hemisferlerde inferior kesimde fokal serebellar displazi, interpedinküler sisternde $4 \times 3.5 \mathrm{~cm}$ boyutlarinda interhemisferisk kist ve hidrosefali (șekil 5a, b), korpus kallozumda hipoplazi (șekil 6) izlendi, Olgu, korpus kallozum hipoplazisi, göz bulguları ve eşlik eden iskelet anomalileri ile Aicardi sendromu tanısı konularak izleme alındı.

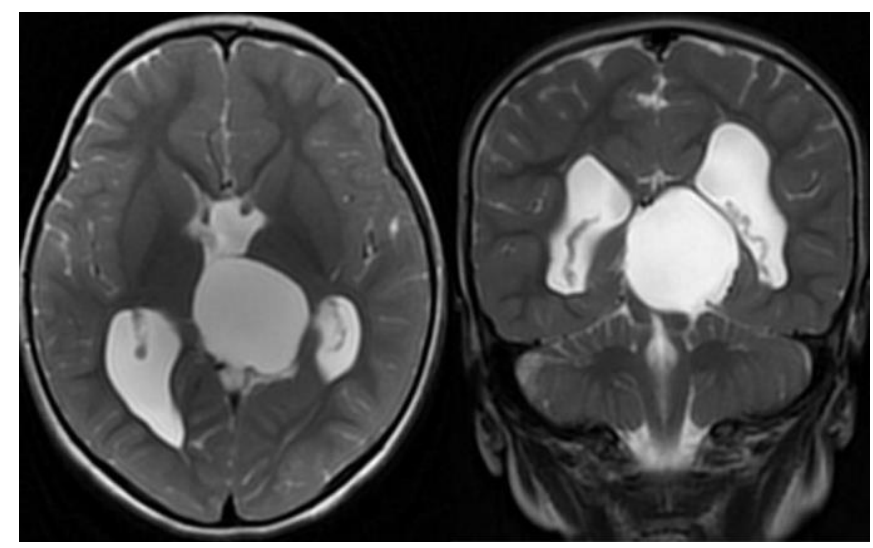

Şekil 5.a. Aksiyel ve b.koronal T2 ağırlıklı görüntülerde interpedinküler sisternde anteriorda serebral aquaduktu basılayıp III. ve lateral ventriküllerde dilatasyona neden olan kist izleniyor.

\section{TARTIŞMA}

Aicardi sendromunun klasik triadı ilk kez 1965 yılında tanımlanmıştır5. DNA onarım mekanizmasındaki bozukluklar sonucu ortaya cıkan, nadir görülen bir genetik hastalıktır. Otozomal resesif geçişlidir. DNA onarım mekanizmasinda yer alan endonükleaz ve eksonükleazları kodlayan kromozomlarda mutasyonlar gösterilmiştir. $\mathrm{Bu}$ nükleazların normal hücrelerden endojen nükleik asit parçacıkları oluşturduğu ve bu parçacıkların IFN aracılı immun cevabı tetiklediği düşünülmektedir6,7. Sadece kızlarda ve $47, \mathrm{XXY}$ karyotipine sahip erkek hastalarda tanımlanmıştır. Ebeveynden geçiş tanımlanmamıştır ${ }^{2,3}$. Erken ve geç başlangıçlı olarak klinik bulgular ortaya çlkabilir; erken başlangıçlı formu 4 aylıktan önce başlar ve erken exitus ile sonuçlanır'. Bir-iki yaş civarında bulguları beliren geç başlangıçlı form normal psikomotor gelişim sonrası görülür9.

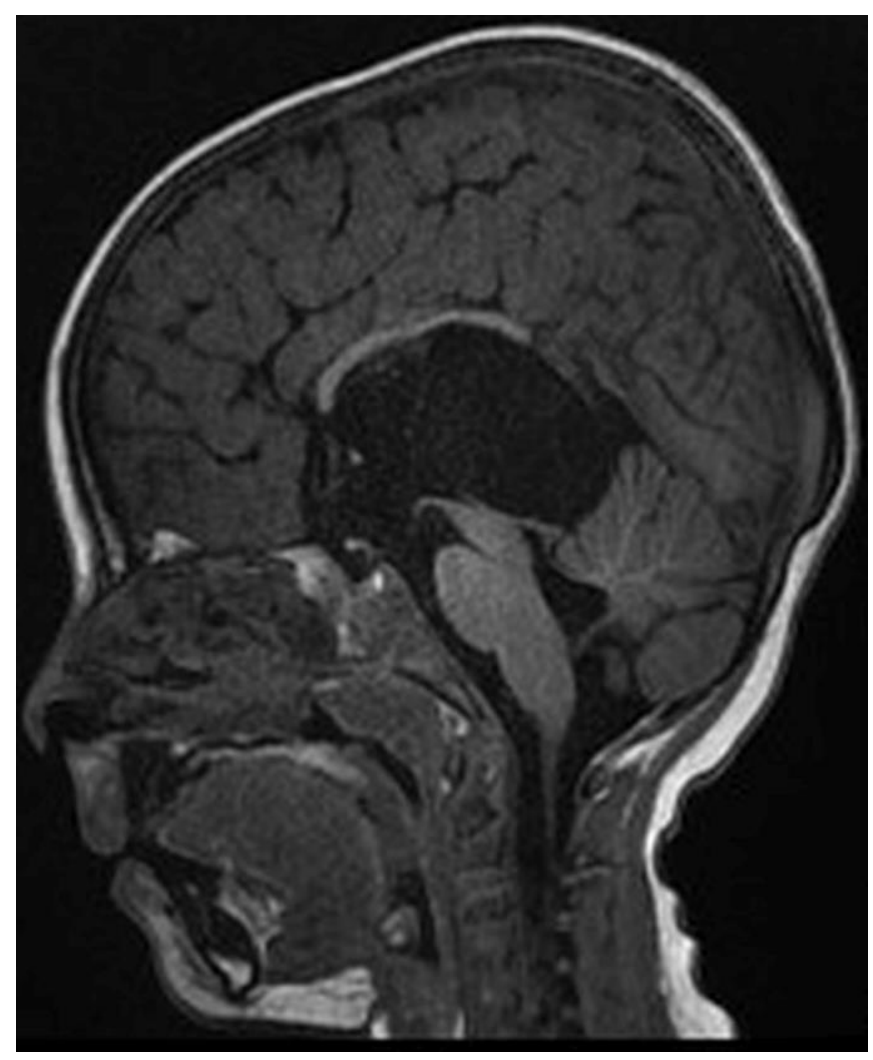

Şekil 6. Sagittal T2 ağırlıklı görüntüde; Korpus kallozum genu ve gövde anterior kesimi hipoplazik olup rostrum, gövde posterior kesimi ve splenium kesimi izlenmiyor. 
Hastalığın tanı kriterleri 1999 yılında Aicardi, 2005 yılında ise Sutton tarafindan modifiye edilmiştir ${ }^{3,10}$. Hastalığın üç kardinal bulgusu; total veya parsiyel korpus kallozum agenezisi, infantil spazmlar, koryoretinal lakünlerdir ve bunlara ek olarak majör bulgular arasında kortikal malformasyonlar, periventriküler ve subkortikal heterotopi, koroid pleksus papillomları, üçüncü ventrikül etrafında veya interhemisferik kistler, optik sinir kolobomu sayılmaktadır-4. Mikroftalmi ve diğer göz anomalileri, vertebral ya da ekstremite anomalileri, serebral hemisferik asimetri, EEG'de hipsaritmi ya da burst-süpresyon ise hastalığın destekleyici bulgularıdır ${ }^{2-4,11}$. Serebral gri maddede heterotopi ve diğer kortikal malformasyonlar epileptik odaktan sorumludur ${ }^{12}$. Sendroma eşlik eden nöbetlerin \%97'si infantil spazm şeklindedir ve daha sıklıkla asimetrik spazmlar gözlenmektedir. Nöbetler çoğunlukla üç ayın altında başlamaktadır ${ }^{2}$. Hastalığın üç kardinal bulgusundan infantil spazmlar ve korpus kallozum agenezisi hastalığa özgül olmadığından koryoretinal lakünlerin saptanması çok önemlidir ${ }^{10}$.

Hastalarda değișen derecelerde mental retardasyon mevcut olup, nadir de olsa nörokognitif olarak normal hastalarda bulunmaktadır ${ }^{12,13}$. Olgularımızdan ilki ağır, ikincisi ise orta derecede mental retarde idi. Sendromun ayırıcı tanısında göz, kraniyal MRG bulguları ve klinik ile toksoplazmoz ve intrauterin sitomegalovirüs enfeksiyonları öne çlkmaktadır ${ }^{2,3}$. Ancak her iki olgumuzunda serolojik belirteçlerinin negatif olması ile bu tanılardan uzaklaşılmıştır. Ayırıca MRG bulguları ve epilepsy ile ayırıcı tanısında, oküloserebrokütanöz sendrom, nöronal migrasyon bozukluklarl, Lennox-Gastaut sendromu, lizensefali, West sendromu bulunmaktadir ${ }^{10}$.

\section{SONUÇ}

Aicardi sendromu vakaları genellikle geç tanı almakta ve benzer kliniğe sahip ikinci veya üçüncü kardeşte tanı konulmaktadır. Mental retardasyonu ve korpus kallozum agenezisi ya da anormal göz muayene bulguları olan özellikle kız hastalar Aicardi sendromu açısından dikkatli incelenmelidir.

Çıkar Çatışması Beyanı: Bu çalışmada çıkar çatışması yoktur.

Finansal Destek: Bu çalışma herhangi bir fon tarafından desteklenmemiştir.

Declaration of ConflictingInterests:There is noconflict of interest in thisstudy.

Financial Disclosure: No financial support was received.

\section{KAYNAKLAR}

1. Banerjee TK, Chattopadhyay A, Manglik AK, et all Aicardisyndrome: a report of fiveIndiancases. NeurolIndia. 2006; 54: 91-93.

2. Aicardi J. Aicardisyndrome. Brain Dev. 2005; 27: 164-71.

3. Aicardi J. Aicardisyndrome: oldandnewfindings. Int Pediatr. 1999; 14: 5-9.

4. Kroner BL, Preiss LR, Ardini MA, et all. New incidence, prevalence, andsurvival of Aicardisyndromefrom 408 cases. J Child Neurol. 2008; 23: 531-5.

5. Aicardi J, Lefebvre J, Lerique-Koechlin A.A newsyndrome: spasm in flexion, callosalagenesis, ocularabnormalities.

ElectroencephalogrClinNeurophysiol. 1965; 19: 60910.

6. Crow YJ, Hayward BE, Parmar R, et all. Mutations in the gene encodingthe $3^{\prime}-5^{\prime}$ DNA exonuclease TREX1 causeAicardi-Goutie 'ressyndrome at the AGS1 locus. NatGenet. 2006; 38: 917-20.

7. Crow YJ, Leitch A,Hayward BE, et all .Mutations in genesencodingribonuclease $\mathrm{H} 2$ subunitscauseAicardiGoutie ressyndromeandmimiccongenitalviralbraininfec tion. NatGenet.2006; 38: 910- 16. 
8. Aicardi J. Aicardi-Goutie`ressyndrome: 11. Fruhman G, Eble TN, Gambhir N, et all. specialtypeearlyonsetencephalopathy. Eur J Ophthalmologicfindings in Aicardisyndrome. J AAPOS. PaediatrNeurol. 2002; 69: A1-A7. 2012; 16: 238-41.

9. D'Arrigo S, Riva D, Bulgheroni S, et all. Aicardi- 12 . Goutie'ressyndrome: description of a lateonsetcase. Dev Med Child Neurol. 2008; 50: 631-4.

12. Rosser TL, Acosta MT, Packer RJ. Aicardisyndrome: spectrum of diseaseandlong-termprognosis in 77 females. Pediatr Neurol. 2002; 27: 343-6.

10. Sutton VR, Hopkins BJ, Eble TN, et all. 13. Grosso S, Lasorellab G, Russo A, et all. Facialandphysicalfeatures of Aicardisyndrome: infantstoteenagers. Am J MedGenet A. 2005; 138A: 2548. Aicardisyndromewithfavorableoutcome: casereportandreview. Brain Dev. 2007; 29: 443-6. 